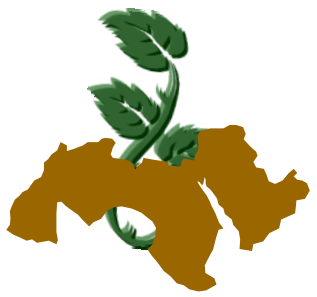

Arab Univ.

J. Agric. Sci., Ain Shams Univ., Cairo, 16(2), 295-306, 2008

\title{
RURAL PEOPLE'S ATTITUDES TOWARDS GIRLS EDUCATION IN SHARKIA AND BENI SUEF GOVERNORATES
}

\author{
Gehan A.G. Elmenofi' ${ }^{1}$ and Yousry A.M. Romiah ${ }^{1}$ \\ 1- Agriculture Extension and Rural Development Research Institute, Agricultural Research \\ Centre, Giza, Egypt
}

Keywords: Rural People Attitudes, Girls Education

\section{ABSTRACT}

The study aimed at identifying rural people's attitudes towards girls education through identifying the attitudes level of rural people, determining the significant differences between interviewees in both Sharkia and Beni Suef governorates, identifying the relationship between studied independent variables and attitudes degree of rural people towards girls education and finally determining the relative contribution of most important variables in explaining the variance in attitudes degree of rural people.

The study was conducted in "Beni Amer and Al-Asloogy" villages from Zagazig district "markaz", Sharkia governorate and "Belfia" and Tazmant AlSharkia" from Beni Suef district "markaz", Beni Suef governorate. Data were collected by personal interview questionnaire after testing its validity, and data were collected during March and April 2007. The following statistical methods were used: Pearson simple correlation coefficient, t-test, stepwise analysis, frequencies and percentages.

The following represent the most important results of the study:

$>$ Rural people attitudes towards girl's education in Sharkia and Beni Suef governorates were positive representing about $53 \%$ and $49 \%$ respectively.

$>$ No significant differences were found between the two studied governorates in regard of attitudes towards girls' education.

$>$ The most important related variables to rural people attitudes towards girls' education in both governorates were: interviewee's age, interviewee's years of education, family's monthly income, interviewee's culture cosmopoliteness, interviewee's participation degree in development projects, social organizations membership, poverty prevalence degree in village from interviewees' point of view and interviewee's perception to local community problems, except family's average age, family size and degree of interviewee's utilization of local community services were effective only in Sharkia governorate.

$>$ Four independent variables explain about $47 \%$ of the variance in the dependent variable (rural people attitudes degree towards girls' education) in Sharkia governorate which are: interviewee's age, satisfaction upon community provided services, interviewee's organization membership, and family's participation in developmental projects.

$>$ Three independent variables explain about $65 \%$ of the variance in the independent variable (rural people attitudes degree towards girls' education) in Beni Suef governorate which are: family's participation in developmental projects, interviewee's years of education and interviewee's organization membership.

> The most important reasons that apprehend rural people from educating their girls in both governorates were: low economic status, people unconvinced with education, traditions and culture that prevent girls' education. Their suggestions to enhance girls' education were: convince and raise rural people's awareness about girls' education, expand school establishments in all villages regarding population density and decrease young girls' laborers phenomena. 


\section{INTRODUCTION}

At the 1994 International Conference on Population and Development (ICPD) in Cairo, 179 countries agreed that population and development are inextricably linked, and that empowering women and meeting people's needs for education and health, including reproductive health, are necessary for both individual advancement and balanced development.

In Beijing and Copenhagen conferences followed by the declaration of child rights document, this issues were strongly tackled and emphasized on universal access to primary education; eliminate the gender gap in primary and secondary education by 2005; and strive to ensure that by 2010 the net primary school enrolment ratio for children. (UNFPA, 2008).

In the third millennium era Arabian countries face great social, economic and political challenges, though developing and improving human resources is an important and vital issue that prevails itself due to its deep impacts on both national and international development. Development is the ideal utilization of all available human and financial capabilities in the community to achieve the pursued development and in same time development does not restricted to one life aspect, but include all aspects; social, economical, cultural, political, educational, legislations and management. (Egyptian State information Service, 2007).

Education dilemma in all its stages and to all community categories is the milestone to overcome and confront all such challenges. Education is one of the fundamental human rights and free education should be provided for all people particularly in the basic elementary stage which were assured in the world declaration of human rights.

Therefore the Egyptian government paid more attention to the education and other relevant issues such as illiteracy, dropout rates from various educational stages, particularly in basic elementary stage, though allocated budget for education increased from L.E. 660 million in 1981/82 to L.E. 18 billion and 800 million in 2000/2001 (National Council for Women, 2003).

The educational system in Egypt extend to more than one and half era, as first official girls school was established "Al-Saniah" from more than 120 years ago, yet illiteracy rates reached to about $40 \%$ and is high among women, particularly in rural areas (Fergany, 2002).

The educational ideology in Egypt emphasis on finding new educational mechanisms and models to provide the appropriate service to deprived areas and attract girls to education i.e. one-class schools, community schools and small-scale schools.

Women educational status no doubt is reflected in many aspects of her private and public life which affects her family and both local and national community (The First Arabian Women Conference, 2000).

In spite of all these exerted efforts, enrollment and dropout rates and illiteracy among girls are still high, for instance; illiteracy gender gap reached its extreme in both Menofia and Qaliobia governorates (37\%), followed by Dakhlia, Gharbia and Aswan governorates (33\%), whereas less gender illiteracy gap was in Damitta and Port said governorates.

Additionally tracking this gap in the period 1976-1996 reveals that in Sharkia governorate the gap was $32 \%$ in 1976, then $27 \%$ in 1986 and became $22 \%$ in 1996 , whereas in Beni Seuf was $31 \%, 31 \%$ and $30 \%$ consequently. These shows that some governorates still suffer from wide gender illiteracy gap such as Beni Suef and Sohag governorates in Upper Egypt, Menofia and Sharkia in Lower Egypt (National Council for Women, 2003).

In regard of enrollment rates in basic elementary stage according to $2000 / 2001$ indicators, the enrollment gap reached $12 \%$ at the state level while it reached its extreme in Matrouh and Menia governorates with about $30 \%$ and $27 \%$ consequently and less enrollment gap was in Kafr AlSheikh governorate with about 2\% (National Council for Women, 2002).

\section{The Study's Problem}

Tracing the various changes in the education system in Egypt in previous era which affected the Egyptian society in general and rural one in particular, indicated that norms, traditions and culture inheritance that distinguished the period pre 1951 revolution prohibited girls education particularly in rural areas, thus high class community educated their girls within their houses in languages and music. After the revolution and by providing free education for all categories some middle-class families started on small scale educating their girls in various sciences and house economics in schools established at that time by people's contributions called "Al-Ahliah" schools then governmental schools (Mousa, 1999 ). 
After expansion of schools whether "Al-Ahliah" or governmental schools in rural areas, people started to change their traditional vision towards girls' education, as girls were considered to end as a wives and mothers, though no need to be educated. The awareness increased, particular after mass media and communication means spread. But with the decreased economic status of rural people, high population density, difficult and complicated educational curriculums, besides existence of some unqualified teachers and many other reasons that led to a kind of defect from girls' education. Though, is this defect caused by the previous raised questions or to other reasons, thus this study tries to answer these questions from rural people's point of view towards girls' education and the following questions forms the study's problem:

1. What is the attitudes level of rural people towards girls' education in Sharkia and Beni Suef governorates?

2. Are there any significant differences between interviewees in Sharkia and Beni Suef governorates regarding girls' education?

3. What is the relationship between studied independent variables and attitudes degree of rural people in regard of girls' education in both governorates?

4. What is the relative contribution of studied independent variables (as total) in explaining the occurred variance in attitudes degrees of rural people towards girls' education in both governorates?

5. What are the recent reasons that apprehend rural people from educating their girls and their suggestions to enhance girls' education?

\section{Study's Objectives}

From the previous review of the study's problem, the study's objectives can be formed as follows:

1. Identify the attitudes level of rural people towards girls' education in Sharkia and Beni Suef governorates.

2. Determine the significant differences between interviewees in Sharkia and Beni Suef governorates regarding girls' education.

3. Identify the relationship between studied independent variables and attitudes degree of rural people in regard of girls' education in both governorates.

4. Determine the relative contribution amount of studied independent variables (as total) in explaining the occurred variance in attitudes de- grees of rural people towards girls' education in both governorates.

5. Determine the recent reasons that apprehend rural people from educating their girls and their suggestions to enhance girls' education in both governorates.

\section{Study's Hypotheses}

To achieve objectives number 2, 3 and 4 the following theoretical hypotheses were formed:

1. There are differences between interviewees in both governorates regarding their attitudes towards girls' education.

2. There are differences between studied independent variables and attitudes degrees of interviewees towards girls' education in both governorates.

3. The studied variables contribute as total in explaining the occurred variance in rural people's attitudes towards girls' education in both governorates.

\section{Study's Sample}

The studied governorates were chosen according to the illiteracy gender gap at the national level, after ranking the governorates, Lower and Upper Egyptian governorates were divided to two categories. Though, Sharkia governorate represented Lower Egypt governorates with an illiteracy gap that reached $22 \%$ and Beni Suef governorate representing Upper Egypt governorates with a gap that reached $30 \%$, which indicates the highest and great gap of illiteracy between males and females. Two districts "markazes" Zagazig and Beni Suef were chosen according to total enrollment rates, as they occupied the first rank which reached 73.4 and 70.8 respectively besides both markazes occupied the first rank in the human development index (0.686 and 0.661 for each). At the village level, four villages were randomly chosen (two from each markaz) "Beni Amer and Al-Asloogy" villages from Zagazig district "markaz" and "Belfia" and Tazmant Al-Sharkia" from Beni Suef district "markaz" (Human Development Report, 2003 \& 2005).

The total sample size was 200 interviewees (100 from each markaz) withdrawn from landholdings registered lists at the agriculture cooperatives and determined according to the following equation (Al-Sayad, and Mustafa, "Anon"): 
$M=N /(N-1) B^{2}+1$

$\mathrm{M}=$ sample size, $\mathrm{N}=$ community size,

$\mathrm{B}=$ standard error $(0.01)$

\section{Data Collection}

Personal interview questionnaire was used to collect data after validity test for its components to be in final form. Data were collected during (MarchApril) 2007.

\section{Statistical Methods}

The following statistical methods were used: Pearson's simple correlation coefficient, T-test between means, ascending multiple regression correlative analysis "step-wise", frequencies and percentages.

\section{Measurement of Study's Variables}

\section{First: Independent Variables}

The following represent the independent variables of which some variables were measured by its crude value such as age and family size whereas others were given relevant weights or codes such as interviewee's culture cosmopoliteness, as a group of places were indicated and each was given a relevant numeric weight and gathered in one value: interviewee's age, average age of interviewee's family, family size, interviewee's years of education, family's average years of education, size of agricultural land ownership, monthly income, degree of culture cosmopoliteness, degree of interviewee's utilization of local community services, interviewee's participation degree in development projects, social organizations membership, poverty prevalence degree in village from interviewees point of view and finally interviewee's perception to local community problems.

\section{Second: Dependent Variable}

Operational definition of the attitudes degree: opinions and trends of rural people towards girls' education and recent factors or reasons that apprehend them from educating their girls. The attitudes degree of rural people towards girls education represent the dependent variable in this study and was measured through an indicator that include 16 statements (negative and positive). These statements were measured on a scale of three responses (agree, neutral, disagree) and given the following weights $(3,2,1)$ respectively for positive statements and vise versa to negative ones, then these weights were summed in one value representing the total degree of the dependent variable.

\section{RESULTS AND GENERAL DISCUSSION}

\section{First: Characteristics of Studied Sample}

The following reveals the characteristics of studied interviewees as shown in Table (1):

- Most of the rural interviewees in Sharkia governorate were in the age category (20-32 years) representing about $60 \%$ of total sample while in Beni Suef were within (34-47 years) representing about $58 \%$ of total sample.

- Most of the rural interviewees in Sharkia governorate were in the medium family size category (6-8 members) representing about $55 \%$ of total sample while in Beni Suef were within the small family size category (3-5 members) representing about $44 \%$ of total sample.

- Most of the interviewees had high educational level representing about $72 \%$ in Sharkia governorate whereas in Beni Suef had low educational level representing about $56 \%$.

- Most of interviewees in Sharkia and Beni Suef governorates regarding family's monthly income fell in the low category representing about $57 \%$ and $61 \%$ respectively.

- Most of interviewees in Sharkia and Beni Suef governorates regarding agriculture land ownership fell in the low category $(0-28)$ representing about $85 \%$ and $49 \%$ respectively.

- Most of the interviewees in Sharkia and Beni Suef governorates had high culture cosmopoliteness representing about $45 \%$ and $33 \%$ respectively.

- Most of the interviewees in Sharkia and Beni Suef governorates had low social organization membership representing about $43 \%$ and $49 \%$ respectively.

Second: Identify the attitudes level of rural people towards girls' education in Sharkia and Beni Suef governorates

To identify the attitudes level of rural people towards girls' education in Sharkia and Beni Suef governorates, results indicated in Table (2) shows that rural people attitudes was positive in both governorates representing about 53\% and $49 \%$ respectively. This could be due to their increased 
Table 1. Personal characterization of studied interviewees in Sharkia and Beni Suef governorates



* 1 feddan=24 kerats

Source: calculated from studied sample (200 interviewees)

Table 2. Distribution of interviewees according to their attitudes level towards girls' education in Sharkia and Beni Suef governorates

\begin{tabular}{|l|c|c|c|c|}
\hline \multicolumn{1}{|c|}{ Categories } & \multicolumn{2}{c|}{ Sharkia } & \multicolumn{2}{c|}{ Beni Suef } \\
\cline { 2 - 5 } & No. & $\%$ & No. & $\%$ \\
\hline Negative (16-26) degree & 60 & 30 & 76 & 38 \\
Neutral (27-37) degree & 35 & 17 & 25 & 13 \\
Positive (+38) degree & 105 & 53 & 99 & 49 \\
\hline
\end{tabular}

Source: studied sample 
awareness and perception towards importance of education in general and girls' education in particular which was not interpreted by real application as there are other factors that apprehend them from educating their girls i.e. cultural norms and traditions and others which will be revealed later.

Third: Determination of the significant differences between interviewees in Sharkia and Beni Suef governorates regarding their attitudes towards girls' education

To test the first statistical hypothesis which is "there is no significant differences between interviewees in both governorates regarding their attitudes towards girls' education". T-test for differences between means in both samples were used and results in Table (3) indicated no significant differences were found between the two governorates regarding their attitudes towards girls' education, as calculated " $t$ " value reached 0.037 which is less than its tabulated value. Accordingly, the statistical hypothesis related to the first theoretical one was accepted.

Forth: Identify the relationship between studied independent variables and attitudes degree of rural people in regard of girls' education in Sharkia and Beni Suef governorates

To determine the studied independent variables that affect rural people attitudes degree towards girls' education in both governorates, the second statistical hypothesis was tested that indicates "there is no significant relationship between studied independent variables and rural people attitudes degree towards girls' education in both governorates". Therefore Pearson simple correlation coefficient was used and results in Table (4) shows the following:

1. Sharkia: there were a positive significant relationship at 0.01 level between the following variables and rural people attitudes degree towards girls' education: interviewee's age, family's average age, family size, interviewee's years of education, family's monthly income, interviewee's culture cosmopoliteness, degree of interviewee's utilization of local community services, interviewee's participation degree in development projects, social organizations membership and poverty prevalence degree in village from interviewees point of view.

Beni Suef: there were a positive significant relationship at 0.01 level between the following variables and rural people attitudes degree towards girls' education: interviewee's age, interviewee's years of education, family's monthly income, interviewee's culture cosmopoliteness, interviewee's participation degree in development projects, social organizations membership and poverty prevalence degree in village from interviewee's point of view. There were a positive significant relationship at 0.05 level between interviewee's perceiveness to local community problems and rural people attitudes degree towards girls' education.

According to these results, the statistical hypothesis was rejected for the significant variables and alternative hypothesis can be accepted.

Additionally, these results indicate that the most related variables to rural people attitudes degree towards girls' education in both governorates were: interviewee's age, interviewee's years of education, family's monthly income, interviewee's culture cosmopoliteness, interviewee's participation degree in development projects, social organizations membership, poverty prevalence degree in village from interviewees' point of view and interviewee's perceiveness to local community problems, except family's average age, family size and degree of interviewee's utilization of local community services were effective only in Sharkia governorate.

Fifth: Determine the relative contribution amount of studied independent (as total) variables in explaining the occurred variance in attitudes degrees of rural people towards girls' education in Sharkia and Beni Suef governorates

To determine the relative contribution amount of studied independent variables (as total) in explaining the occurred variance in attitudes degrees of rural people towards girls' education in Sharkia and Beni Suef governorates, ascending multiple regression correlative analysis "step-wise" was used to test the third statistical hypothesis that indicates "there is no significant relationship between studied independent variables (as total) and rural people attitudes degree towards girls' education in both governorates".

\section{The following results were revealed}

1. Sharkia: Table (5) shows the significant of the model until step four of the analysis, as multi regression correlative coefficient amounted 0.678 which is significant at 0.01 and calculated " $F$ " value reached 43.610 which means that there are four independent variables contribute in explaining the 
Table 3. Differences between interviewees in Sharkia and Beni Suef governorates regarding their attitudes towards girls' education

\begin{tabular}{|c|c|c|c|c|}
\hline Item & Sample Size & Arithmetic Mean & Standard Deviation & \multirow{2}{*}{ "t" value } \\
\hline Governorates & 200 & 31.700 & 10.26092 & \multirow{2}{*}{0.037} \\
\cline { 1 - 3 } Sharkia & 200 & 31.7400 & 11.27689 & \\
\hline
\end{tabular}

Source: studied sample

Table 4. Simple correlation coefficient values of the relationship between studied independent variables and rural people's attitudes towards girls' education in Sharkia and Beni Suef governorates

\begin{tabular}{|c|c|c|}
\hline \multirow{2}{*}{\begin{tabular}{|r} 
Values \\
Independent variables \\
\end{tabular}} & \multicolumn{2}{|c|}{ Simple correlation values } \\
\hline & Sharkia & Beni Suef \\
\hline Age & $0.579 * *$ & $0.177^{* *}$ \\
\hline Family's average age & $0.503^{* *}$ & 0.077 \\
\hline Family size & $0.214^{* *}$ & 0.033 \\
\hline Years of education & $0.281^{* *}$ & 0.288 ** \\
\hline Family's years of education & 0.121 & 0.033 \\
\hline Agriculture land holding ownership & 0.014 & 0.029 \\
\hline Family's monthly income & $0.221^{* *}$ & $0.275^{* *}$ \\
\hline Culture cosmopoliteness & $0.371^{* *}$ & $0.490 * *$ \\
\hline Interviewee's utilization of local community services & $0.247^{* *}$ & 0.044 \\
\hline Interviewee's participation degree in development projects & 0.236 ** & $0.547 * *$ \\
\hline Social organizations membership & $0.181^{* *}$ & $0.227^{* *}$ \\
\hline $\begin{array}{l}\text { Poverty prevalence degree in village from interviewees } \\
\text { point of view }\end{array}$ & 0.210 ** & 0.229 ** \\
\hline Interviewee's perceiveness to local community problems & 0.061 & 0.138 * \\
\hline
\end{tabular}

** Significant at $0.01 \quad$ * significant at 0.01

Source: studied sample

occurred variance in dependent variable: interviewee's age, interviewee's utilization of local community services, social organizations membership and interviewee's participation degree in development projects. Determinative coefficient value $\left(R^{2}\right)$ of these variables amounted 0.47 that means the these four variables together explain about $47 \%$ of the occurred variance in the dependent variable in Sharkia governorate and the remained percentage $53 \%$ is due to other variables not included in this study.
According to these results, the third statistical hypothesis was rejected regarding the following variables: interviewee's age, interviewee's utilization of local community services, social organizations membership and interviewee's participation degree in development projects and the alternative hypothesis can be accepted regarding these variables.

2. Beni Suef: Table (6) shows the significant of the model until step three of the analysis, as multiple regression correlative coefficient amounted 
Table 5. Results of step-wise analysis of the independent variables affecting rural people's attitudes towards girl's education in Sharkia governorate

\begin{tabular}{|c|c|c|c|c|}
\hline $\begin{array}{c}\text { Independent } \\
\text { Variable in } \\
\text { model }\end{array}$ & $\begin{array}{c}\text { Multiple } \\
\text { Correlation } \\
\text { coefficient }\end{array}$ & $\begin{array}{l}\text { Accumulative \% } \\
\text { of occurred } \\
\text { variance in } \\
\text { dependent } \\
\text { variable }\end{array}$ & $\begin{array}{l}\text { Explained } \% \text { of } \\
\text { occurred } \\
\text { variance in } \\
\text { dependent } \\
\text { variable }\end{array}$ & "F" value \\
\hline Interviewee's age & 0.579 & 0.33 & 0.33 & 100.073 ** \\
\hline $\begin{array}{l}\text { Interviewee's utilization of local } \\
\text { community services }\end{array}$ & 0.619 & 0.38 & 0.05 & $61.295^{* *}$ \\
\hline Social organizations membership & 0.663 & 0.43 & 0.05 & $51.265^{* *}$ \\
\hline $\begin{array}{l}\text { Interviewee's participation degree } \\
\text { in development projects }\end{array}$ & 0.678 & 0.47 & 0.04 & $43.610^{* *}$ \\
\hline
\end{tabular}

** Significant at 0.01

Source: studied sample

Table 6. Results of step-wise analysis of the independent variables affecting rural people's attitudes towards girl's education in Beni Suef governorate

\begin{tabular}{|l|c|c|c|c|}
\hline Analysis results & $\begin{array}{c}\text { Multiple } \\
\text { correlation } \\
\text { coefficient }\end{array} \begin{array}{c}\text { Independent } \\
\text { Variable in } \\
\text { model }\end{array}$ & $\begin{array}{c}\text { Accumulative \% } \\
\text { of occurred } \\
\text { variance in } \\
\text { dependent } \\
\text { variable }\end{array}$ & $\begin{array}{c}\text { Explained \% of } \\
\text { Occurred } \\
\text { variance in } \\
\text { dependent } \\
\text { variable }\end{array}$ & "F" value \\
\hline Interviewee's participation de- & 0.719 & 0.51 & 0.51 & $211.687^{* *}$ \\
gree in development projects & 0.775 & 0.60 & 0.09 & $147.939^{* *}$ \\
\hline Interviewee's years of education & 0.812 & 0.65 & 0.05 & $126.283^{* *}$ \\
\hline Social organizations member- \\
ship
\end{tabular}

** Significant at 0.01

Source: studied sample

0.812 which is significant at 0.01 and calculated "F" value reached 126.283 which means that there are three independent variables contribute in explaining the occurred variance in dependent variable: interviewee's participation degree in development projects, interviewee's years of education, social organizations membership. Determinative coefficient value $\left(R^{2}\right)$ of these variables amounted 0.65 that means the these three variables together explain about $65 \%$ of the occurred variance in the dependent variable in Sharkia governorate and the remained percentage $35 \%$ is due to other variables not included in this study.

According to these results, the third statistical hypothesis was rejected regarding the following variables: interviewee's participation degree in development projects, interviewee's years of education, social organizations membership and the alternative hypothesis can be accepted regarding these variables. 
The previous results indicate that the most effective variables on rural people's attitudes degree towards girls' education in both governorates were: interviewee's years of education, social organizations membership and interviewee's participation degree in development projects, except the following variables: interviewee's age and interviewee's utilization of local community services were only effective in Sharkia governorate and with no impact in Beni Suef governorate.

These results could be due to that these factors contributed in increasing rural people's awareness regarding education in general and girls education in particular besides rural people's exposition to various experiences ascribed from their participation in various social organizations and developmental projects plays an important role in increasing their perceiveness towards girls' education specially when dealing with successful women working in such projects or in NGOs, also the training courses they receive are important key elements in promoting rural people's concepts and visions that copes with the national and international changes.

Sixth: Reasons that apprehend rural people from educating their girls and their suggestions to enhance girls' education in both governorates

\section{Reasons that apprehend people from edu- cating their girls}

It was important to identify the real reasons behind apprehending girls' education, though various stakeholders in NGOs, development programs and projects, educational institutions can take into consideration such reasons and set appropriate solutions to be included in recent and future educational plans of action.

The results in Table (7) indicate that the most important reasons that apprehend rural people from educating their girls in Sharkia and Beni Suef governorates were as follows: girls early marriage (58\%, 50\% respectively), girls help in house work (42\%, 23\% respectively), family not interested in education (38\%, 44\% respectively), family's low income $(31 \%, 22 \%$ respectively), far distance of school (26\%, $20 \%$ respectively), high costs of special tutoring $(21 \%, 20 \%$ respectively) and lack of parents awareness (21\%, $16 \%$ respectively).

These indicate that in spite of all exerted efforts in education in general and girls' education in particular there are still some obstacles and problems that apprehend girls' education nowadays. Some of these reasons are related to economic reasons such as family low income which shows high poverty rates and costs of living among rural people therefore the head of household re-consider and set his own priorities considering his own budget and secures his family's livelihoods. Other reasons are culture inheritance that still affect girls' education one way or another, besides some schools in certain educational stages are far (preparatory and secondary), so they don't want their girls to move out their villages.

These entire reasons implant the prevalence of such phenomena and could be extended to include boys also which threaten the quality of human power resources in Egypt, besides high illiteracy rates not only among adults but also youth and high dropout rates. Therefore, serious actions and procedures should take place regarding the educational institutions itself and all relevant stakeholders (curriculum, teachers, schools and facilities) from one hand and rural people livelihoods from another and try to reach an appropriate combination between all previous mentioned reasons.

\section{Suggestions to enhance girls' education from interviewees point of view}

It was vital to identify rural people's opinion in enhancing girls' education within their communities to achieve strong and developed ones and assure good quality of human resources that can confront all changes either on national or international level and also to address policy makers and those responsible of educational policies to take all factors and suggestions into consideration. Additionally, a future action that support and assure public attitudes and attitudes towards education in general and girls' education in particular is needed.

The results in Table (8) indicated that the most important suggestions in Sharkia and Beni Suef governorates were: convince and raise rural people's awareness about girls' education (73\%, 51\% respectively), expand school establishments in all villages regarding population density $(46 \%, 28 \%$ respectively), confront special tutoring phenomena (45\%, 46\% respectively), enact legislations that raise girls marriage age (23\%, $26 \%$ respectively), decrease young girls laborers phenomena $(21 \%$, $18 \%$ respectively) and finally train teachers and qualify them to deal with girls $(16 \%, 6 \%$ respectively). 
Table 7. Reasons that apprehend rural people from educating their girls in Sharkia and Beni Suef governorates

\begin{tabular}{|l|l|l|l|l|}
\hline \multirow{2}{*}{\multicolumn{1}{|c|}{ Reasons }} & \multicolumn{2}{c|}{ Sharkia } & \multicolumn{2}{c|}{ Beni Suef } \\
\cline { 2 - 5 } & No. & $\%$ & No. & $\%$ \\
\hline Girls early marriage & 115 & 58 & 99 & 50 \\
Girls help in home works & 83 & 42 & 45 & 23 \\
Family not interested in education & 75 & 38 & 88 & 44 \\
Family low income & 61 & 31 & 44 & 22 \\
Far distance of school & 52 & 26 & 39 & 20 \\
High costs of special tutoring & 41 & 21 & 39 & 20 \\
Lack of parents awareness & 41 & 21 & 32 & 16 \\
\hline
\end{tabular}

Source: studied sample

Table 8. Suggestions to enhance girls' education from interviewees point of view in Sharkia and Beni Suef governorates

\begin{tabular}{|l|c|c|c|c|}
\hline \multirow{2}{*}{\multicolumn{1}{|c|}{ Suggestions }} & \multicolumn{2}{c|}{ Sharkia } & \multicolumn{2}{c|}{ Beni Suef } \\
\cline { 2 - 5 } & No. & $\%$ & No. & $\%$ \\
\hline convince and raise rural people's awareness about & 145 & 73 & 102 & 51 \\
girls' education & & & & \\
Expand school establishments & 92 & 46 & 56 & 28 \\
Confront special tutoring phenomena & 89 & 45 & 91 & 46 \\
enact legislations that raise girls marriage age & 45 & 23 & 51 & 26 \\
Decrease young girls laborers phenomena & 42 & 21 & 35 & 18 \\
Training teachers and qualify them to deal with girls & 31 & 16 & 12 & 6 \\
\hline
\end{tabular}

Source: studied sample

\section{REFERENCES}

Al-Sayad, A.B. and G.M. Mustafa, (ANON). Statistical Sampling, Ain Shams Stationary Publications, p. 109, Cairo, Egypt.

Egyptian State Information Service, Ministry of Information, Development of Human Resources, Cairo Retrieved in November 2007, http://www.sis.gov.eg

Fergany, N. (2002). Empowering Women, A milestone of a humanitarian up rise in Egypt, submitted to the National Council for Women, p. 9, Cairo, Egypt.

Human Development Report (2003 \& 2005). Organization of Reconstruction and Development of Egyptian Village "ORDEV" and UNDP, Sharkia governorate (2003) pp. 54 \& 61 and Beni Suef Governorate (2005), p. 22 \& p. 29, Cairo, Egypt.
Mousa, Nabawia (1999). My History, $3^{\text {rd }}$ Ed., p. 12. Max Group Publications, Cairo, Egypt. National Council for Women (NCW) (2000). The First Arabian Women Conference, 18-20 November, Researches and Studies, p. 81, Cairo, Egypt.

National Council for Women (NCW) (2003). Development of Women's Status in Mubarak Regime (1981-2002), p. 77 \& p. 93, Cairo, Egypt.

National Council for Women, (NCW) (2002). A Statistical Glimpse on Women Status in Egypt, March 2002, p. 4, Cairo, Egypt.

UNFPA, United Nations Population Fund, International Conference on Population and Development, Retrieved in January 2008, http://www.unfpa.org/icpd/icpd poa.htm 